\title{
Analysis of the influence of shield construction on the surrounding ground surface settlement
}

\author{
Li Bing, Ji Fengying \\ School of Civil Engineering, Shenyang Jianzhu University, Liaoning Shenyang, 110168
}

Key words : Shield construction, Surface subsidence, influence factor

\begin{abstract}
Based on the background of a double line shield tunnel in Shenyang metro, the construction process of double line shield is simulated by using the finite element analysis software of GTS Midas. The change course of ground surface settlement during construction and the influence of the physical and mechanical properties of soil on the ground surface settlement are studied. The obtained results have certain guiding significance for the construction of similar double line metro shield tunneling. Research results: (1) In most of the excavation and has not yet been lining construction process, settlement of ground surface often appear bigger change. (2)The elastic modulus of soil is gradually increased, and the land subsidence is getting smaller and smaller. But when the elastic modulus is increased to $100 \mathrm{Mpa}$, the surface periphery may be elevated. (3)With the internal friction angle of the soil decreased, the amount of land subsidence is more and more large. And the surface periphery may be elevated. (4)The correction coefficient $n=0.84$ values are converted to the revised calculated values and measured values are close. However, there is a need for further analysis and Research on the change trend of the settlement.
\end{abstract}

\section{Introduction}

At present, many cities are facing serious transportation problems, the ground transportation space has been unable to meet the needs of people, so the subway has become an important means of transportation in the city. At the same time, using the shield method to construct subway construction has become a new trend of subway construction. In the process of shield tunneling, the shield machine is constantly grinding, cutting, digging rock and soil mass, so that the surrounding rock and soil around a certain range of the settlement and deformation. Therefore, many scholars at home and abroad have carried out a lot of research and Analysis on this technology. The shield construction in Shenyang Metro for example using three-dimensional finite element analysis software simulation and analysis of the interval, by changing the factors to study the variation of ground surface settlement, to provide some reference for improving the efficiency of the shield construction.

\section{Engineering survey}

Shenyang Metro is a double line tunnel, the shield method is used to carry out construction. The project to promote the use of slurry balance shield machine, a total length of 1600 meters single line. Because the shield construction is longer in length, this paper only selects a section of the interval for modeling and analysis. Shield excavation tunnel is a circular tunnel, tunnel diameter $6.24 \mathrm{~m}$, diameter for $5.54 \mathrm{~m}$, thickness of the is $0.35 \mathrm{~m}$, segment ring is $1.5 \mathrm{~m}$ wide. Each ring segment consists of six prefabricated reinforced concrete segment blocks, which contains three standard block, two adjacent to a block and a cap. The main types of the soil around shield are silty clay and sand, and the sand types mainly include fine sand, round gravel and gravel sand. 


\section{The establishment of calculation model and analysis}

\subsection{The establishment of calculation model}

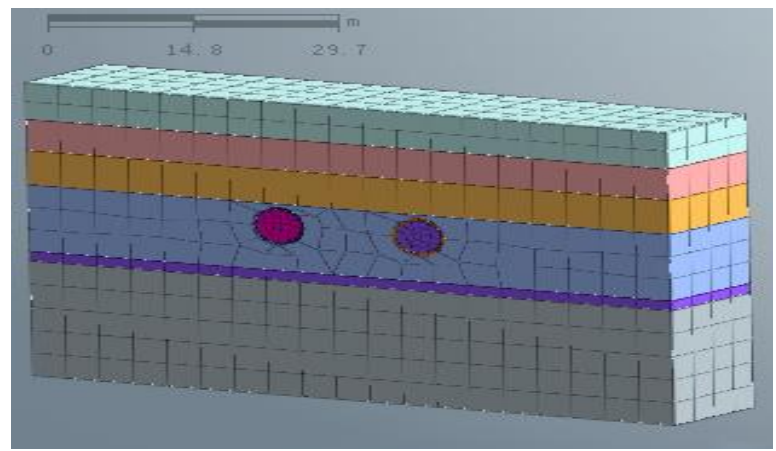

Figure 1. Schematic diagram of the overall calculation model

In this paper, the three-dimensional finite element analysis software GTS Midas is used to simulate and analyze. Model selection size is $80 \mathrm{~m} * 50 \mathrm{~m} * 15 \mathrm{~m}$ cuboid soil, in the soil of double shield construction, two parts of the tunnel are circular tunnel, tunnel diameter $6.24 \mathrm{~m}$, two circular tunnel axis distance is $17 \mathrm{~m}$, in the center of the tunnel buried deep $20.63 \mathrm{~m}$, overlying soil thickness $17.51 \mathrm{~m}$. The shield construction each excavation length is $1.5 \mathrm{~m}$, the 10 step $(15 \mathrm{~m})$ of the finite element analysis is shown in Figure 1.

\subsection{Calculation of shield construction model}

In this paper, the basic principle of the finite element method is applied in the construction of the model, according to the actual construction method, to define the construction stage. After setting the analysis process, the result is the construction process of the shield method. According to the actual situation of the project, the construction method of the double line shield is adopted separately, and the construction process is not carried out at the same time.

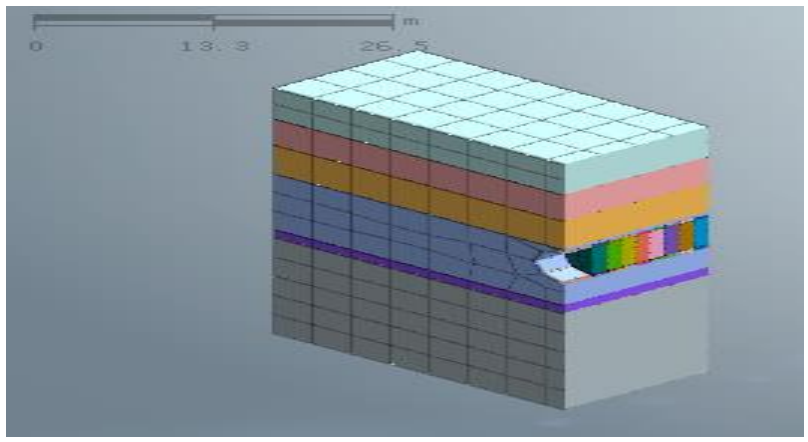

Figure 2. Sketch map of excavation steps

During the simulation of shield tunnel, the excavation process is realized mainly through the activation and passivation of the element, load and boundary conditions. In the initial stress analysis phase, all the original units are activated before the initial stress analysis, and the displacement is cleared. The first step is to simulate the construction process, the first step, the shield machine to the soil to carry out the excavation of the top thrust, that is, passivation of the first 1,2 ring and the outer circle of the soil element, while the activation of the 1,2 ring shield to stabilize the surrounding soil. In the second step, passivation of the soil elements of the inner and outer rings of the 3,4, and the 3,4 ring shield shell is activated to stabilize the surrounding soil mass. In the third step, passivation of the soil elements of the inner and outer rings of the 5,6, and the 5,6 ring shield shell is activated to stabilize the surrounding soil mass. The installation start segment in the completion of the three step after excavation. In the fourth step, passivation of the soil elements of the inner and outer rings of the 7,8, and the 7,8 ring shield shell is activated to stabilize the surrounding soil mass. At the same time, the activation of the 1,2 ring unit and corresponding boundary conditions and applied force, so as to complete the installation of the 1,2 ring. In the fifth step, passivation of the soil 
elements of the inner and outer rings of the 9,10, and the 9,10 ring shield shell is activated to stabilize the surrounding soil mass. At the same time, the activation of the 3,4 ring unit and corresponding boundary conditions and applied force, so as to complete the installation of the 3,4 ring. When the 1,2 ring has been installed, the shield segment structure and two separated, namely passivation of 1,2 shield ring. Finally, the grouting of shield tail and the hardening of soil mass. By analogy, continuous cycle until this process in double line tunnel are excavation is completed, the shield method construction of the whole process is shown in Figure 2.

\subsection{Analysis of surface subsidence process}

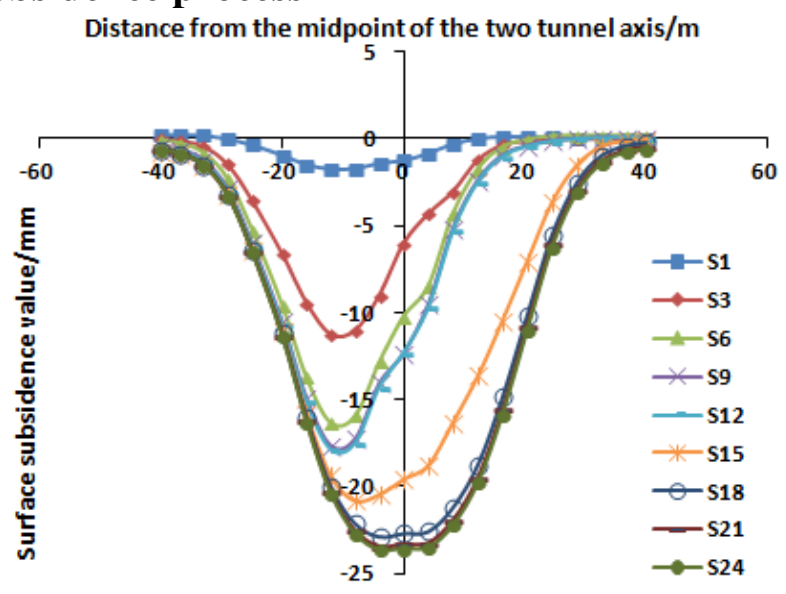

Figure 3. At the end of the construction phase at $\mathrm{Y}=0 \mathrm{~m}$ the surface of the earth's surface

From Figure 3 we can see that in the stage of S1 completion, the tunnel excavation of the left line of 3 meters without lining construction, surface subsidence maximum value of $-1.75 \mathrm{~mm}$ appear in the left line tunnel axis position. Due to the role of Shield Thrust, 17 meters away from both sides of the axis, the surface appeared tiny uplift, the maximum value of $0.23 \mathrm{~mm}$. In stage $\mathrm{S} 3$ is completed, the left tunnel excavation 9 meters maximum settlement for $-11.29 \mathrm{~mm}$ close to the settlement of the whole half of the maximum value, on both sides of the bulge deformation disappeared, the change of settlement is obvious. In stage S6 is completed, the left line excavation has been completed, and has been gradually completed 9 meters in front of segment lining and the former 6 meters shield shell from the segment part of construction. At this time, the surface subsidence maximum value for $-16.33 \mathrm{~m}$, settlement and deformation is also more obvious.

In S7-S12 stage shield left line excavation has been completed, the main segment lining, shield shell detachment and grouting and hardening construction, surface subsidence than before excavation part changed little. Subsequent S13-S24 part for the right line of the shield construction, construction method and the left line exactly the same, also in S15 settlement more obvious changes, due to the similar stage of S3 tunnel excavation completed construction of lining has not been made. The S18 stage is similar to the S6 stage excavation and a part of the lining construction has been completed. S19-S24 stage is mainly carried out similar to the S7-S12 stage construction, the same amount of surface subsidence change is smaller and gradually tend to be stable.

\section{The surface subsidence analysis under the influence of different parameters}

\subsection{Elastic modulus of soil in Shield Tunneling}

32.2Mpa for the actual elastic modulus of the original model in the fourth layer of soil, in the elastic modulus of the soil to $25 \mathrm{MPa}$. $50 \mathrm{MPa}, 100 \mathrm{MPa}, 200 \mathrm{MPa}$, maximum surface settlement values were $-33.17 \mathrm{~mm},-11.95 \mathrm{~mm},-1.56 \mathrm{~mm}$ (uplift maximum 1.90mm), 3.60mm (uplift). 


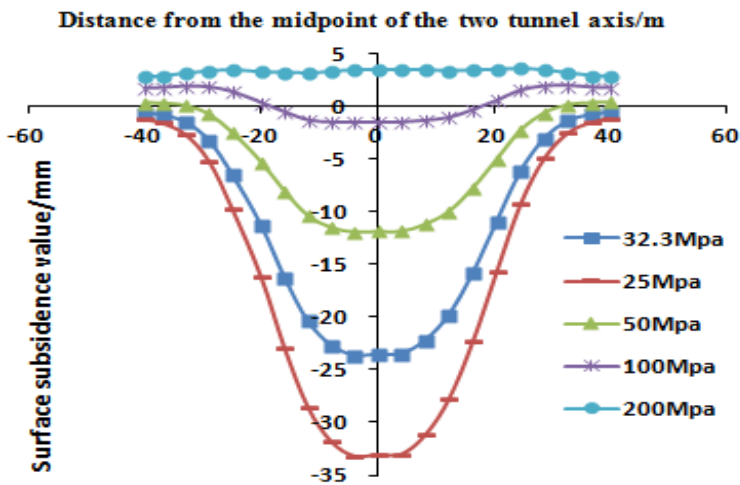

Figure 4. Comparison of surface settlement of $\mathrm{Y}=0$ with different elastic modulus

As can be seen from Figure 4, the amount of ground subsidence in different soil layers of elastic modulus, produced a significant change in the trend. Along with the increase of the elastic modulus of the shield construction in the soil layer, the numerical value of the ground settlement shows the opposite trend. When the elastic modulus of the soil layer is $100 \mathrm{Mpa}$, in the range of 20 meters outside the tunnel axis, resulting in uplift phenomenon. When the elastic modulus of the soil layer reaches $200 \mathrm{Mpa}$, the bulge deformation is common on the ground.

\subsection{Internal friction angle of soil in Shield Tunneling}

And analysis of the elastic modulus of the method is similar to the fourth layer of soil selected 32 degrees, 24 degrees, 16 degrees, 8 degrees, four degrees of internal friction angle degrees and the original model of the friction angle of 36.4 degrees for the comparative analysis. Under the influence of the internal friction angle of the internal friction angle and the internal friction angle of the original soil layer, the comparison of the curves of the surface subsidence under the influence of the internal friction angle is shown in figure 6. It is assumed that internal friction angle of fourth layers of soil is 32 degrees, 24 degrees, 16 degrees, 8 degrees, the maximum value of the ground surface subsidence is $-28.04 \mathrm{~mm},-32.22 \mathrm{~mm},-37.74 \mathrm{~mm},-45.57 \mathrm{~mm}$.

From Figure 5 shows that the friction angle of the soil will have a great impact on the surface subsidence. When the internal friction angle is 8 degrees, the settlement is the maximum, and the internal friction angle is the minimum when the internal friction angle is 36.4. With the gradual increase of the friction angle of the soil, the maximum value of the ground surface settlement can be effectively reduced. And, the construction of the case, easy to cause the uplift of the surrounding soil deformation. When the friction angle of the soil is relatively small, the change of the internal friction angle will bring great changes to the settlement. And when the internal friction angle of 24 degrees or more, the impact of the angle of the surface settlement will be far less than the impact of 24 degrees.

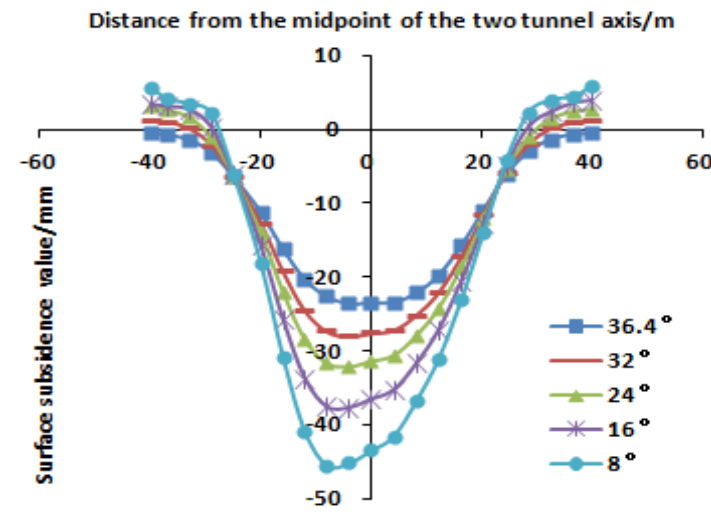

Figure 5. Comparison of surface settlement of $Y=0$ with different internal friction angle 


\section{Empirical formula of maximum subsidence of correction}

From Figure 6 empirical formula method and finite element method to simulate the surface settlement changes comparison chart can be seen, the two methods in maximum settlement value and most of the other sites sedimentation value although very similar, but there is still a little gap. This combined with the measured values for further analysis.

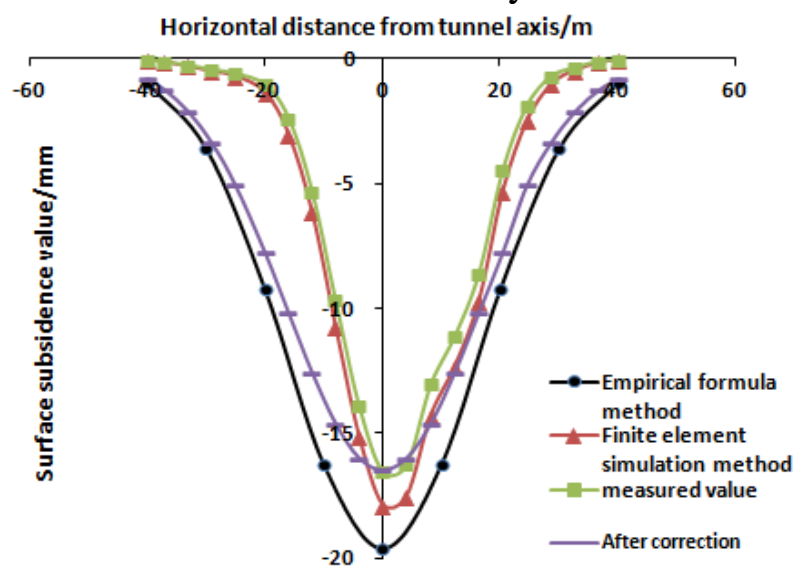

Figure 6. Using different methods to calculate the results of surface subsidence comparison chart

According to the measured value of this paper, the maximum settlement of empirical formula is modified by adding the correction factor $\mathrm{N}$, which makes the maximum value of the measured value and the maximum value calculated by empirical formula more close to.

$$
\mathrm{S}_{\text {max }}=\mathrm{n} \cdot \frac{\mathrm{V}_{\mathrm{s}}}{\mathrm{i} \cdot \sqrt{2 \pi}} \approx \mathrm{n} \cdot \frac{\mathrm{V}_{\mathrm{s}}}{2.5 \cdot \mathrm{i}}
$$

Based on the analysis and summary of the measured and empirical values, the correction coefficient $\mathrm{n}$ of the maximum settlement value formula (1) is $0.82 \sim 0.94$. According to the $\mathrm{N} 0.84$, the maximum value of the settlement is in agreement with the measured value. For the modified settlement after the maximum value of the empirical formula can reach an agreement with the measured, but of settlement and the change trend remains to be further analysis and research, hope follow-up with more examples to provide research basis.

\section{Conclusion}

In this paper, the finite element analysis software of Midas-GTS is used to simulate the construction process of Double Line Metro shield. According to the results, the maximum and the change course of the surface subsidence is studied. Draw the conclusion as follows:

(1) Taking a shield section of Shenyang Metro as the research object, the change course of ground surface settlement during the construction process is simulated. The results show that the maximum value of the ground surface settlement is $-23.67 \mathrm{~mm}$. Analyzed and summarized in most of the excavation and has not yet been carried out construction of lining construction process, settlement of ground surface often appear bigger change; and in the segment lining, grouting and soil hardening construction process, the occurrence of surface subsidence change is not obvious.

(2) The elastic modulus of the soil will result in a large change in the ground settlement of each monitoring point. With the increase of the elastic modulus of the soil, the ground settlement is getting smaller and smaller. Form the construction condition of this paper, when the elastic modulus increases to $100 \mathrm{Mpa}$, the uplift deformation will occur on the surface of the earth.

(3) The internal friction angle of the soil has obvious influence on the ground settlement, with the decrease of the internal friction angle of the soil, the ground settlement is more and more large. Moreover, in this case, the construction easy to cause the uplift of the surrounding soil deformation.

(4) According to the maximum value in practical measured ground surface settlement, the empirical formula of the maximum settlement amount is corrected, after the measured values and the empirical values of the comparative analysis, as well as a reference to the data in other 
literatures, and obtain a correction coefficient $\mathrm{n}$ of the appropriate range for 0.82 0.94. And according to the $\mathrm{n}$ is taken to be 0.84 and experience formula calculation value and the measured value achieve consistent, and for the settlement quantity changes remains to be further analysis and research.

\section{References}

[1] Wu Xianguo, Wang Yanhong, Miao Xiang, Wang Chunliang, Yang Qiongpeng, Zhang Limao. Key parameters analysis of surface subsidence induced by tunneling construction[J]. Journal of Civil, Architectural \& Environmental Engineering, 2015, Vol.37(No.2): 8 15. (in Chinese)

[2] Tong Xuejun, Yue Pengfei, Liu Chongqing. Numerical Calculation and Example Analysis of Ground Settlement Due to Tunnel Shield Construction[J]. Journal of Langzhou Jiaotong University, 2011, Vol.30(No.1) : 86 89. (in Chinese)

[3] Zhang Haibo, Yin Zongze, Zhu Jungao. Analysis of the surface settlements due to shield tunneling[J]. Railway Construction Technology, 2005(1), Tunnel underground engineering: 32 35. (in Chinese)

[4] ZHANG Hai-bo, YIN Zong-ze, ZHU Jun-gao, LI Cui-xia. Three-dimensional FEM simulation of shield-driven tunnel lining during construction stage[J]. Rock and Soil Mechanics, 2005, Vol.26(No.6) : 990 994. (in Chinese)

[5] WANG Li-zhong, LÜ Xue-jin. A complex variable solution for different kinds of oval deformation around circular tunnel in an elastic half plane[J]. Chinese Journal of Geotechnical Engineering, 2007, Vol.29(No.3): 319 327. (in Chinese)

[6] YU De-hai, ZHANG Tao, JIANG An-nan. Analysis of Influencing Factors of Metro Shield Construction under Complicated Conditions[J]. JOURNAL OF RAILWAY ENGINEERING SOCIETY, 2015, No.5: 86 91. (in Chinese)

[7] LI Qing, YANG Lu, WANG Chang. Analysis on ground surface settlement caused by subway shield construction[J]. TECHNOLOGICAL DEVELOPMENT OF ENTERPRISE, 2011, No.5: 85 87. (in Chinese)

[8] Qian Fanga,Dingli Zhanga,QianQian Lia,Louis Ngai Yuen Wongb.Effects of twin tunnels construction beneath existing shield-driven twin tunnels.Tunnelling and Underground Space Technology,2015(Vol.45):128 137

[9] L. Ran,X. W. Ye,G. Ming,X. B. Dong,Fei Kang.Structural Monitoring of Metro Infrastructure during Shield Tunneling Construction.The Scientific World Journal, 2014(Vol.2014)

[10]Jiangfeng Liu,Taiyue Qi,Zhanrui Wu.Analysis of ground movement due to metro station driven with enlarging shield tunnels under building and its parameter sensitivity analysis.Tunnelling and Underground Space Technology incorporating Trenchless Technology Research,2012(Vol.28):287 296

[11]Zhang Ji-Chao,Liu Chen,Liu Mao-Long,Xu Yong,Lin Ben-Hai,Zheng Xian-Chang.Research and application on the key technologies of the underground space of Zhujiang New Town in Guangzhou.GongchengLixueEngineeringMechanics,2010(Vol.27,Suppl 2):114 123

[12]Jin-Sun Lee.An application of three-dimensional analysis around a tunnel portal under construction.Tunnelling and Underground Space Technology incorporating Trenchless Technology Research,2009(Vol.24 (6)):731 738 